\title{
Prevalence of porcine circovirus-like agent P1 in Jiangsu, China
}

\author{
Libin Wen ${ }^{1}$, Kongwang He ${ }^{1 *}$, Hanchun Yang ${ }^{2}$, Zhengyu Yu', Aihua Mao ${ }^{1}$, Shulin Zhong ${ }^{1}$, Yanxiu Ni', \\ Xuehan Zhang ${ }^{1}$, Bin Li ${ }^{1}$, Xiaomin Wang ${ }^{1}$, Junming Zhou', Rongli Guo ${ }^{1}$, Lixin Lv and Jieyuan Jiang ${ }^{1}$
}

\begin{abstract}
Recently, we identified a novel porcine circovirus type 2-like agent P1 isolate from swine. The present study represents the first survey of $\mathrm{P} 1$ prevalence in swine herds from Jiangsu, China, by using PCR targeting the complete genome of P1. Prevalences of 50\% and 19\% were found among 6 herds and 248 animals, respectively. The results indicate a high prevalence of P1 in China pig populations.
\end{abstract}

Keywords: Porcine circovirus type 2-like agent P1, Prevalence, PCR, China

\section{Introduction}

Porcine circovirus (PCV), belonging to the family Circoviridae, is a small non-enveloped virus with a circular, single-stranded DNA genome. To date, two types of porcine circoviruses have been recognized: PCV1 and PCV2. PCV1 was originally isolated from the porcine kidney cell line PK15 [1] and did not induce a disease in swine [2], while PCV2 has recently been identified as the causal agent of postweaning multisystemic wasting syndrome (PMWS) [3,4]. The major clinical signs of PMWS are progressive wasting and growth retardation, pallor of the skin, and occasional icterus $[5,6]$.

PCV2-like agent (designated P1) was discovered by accident in 2007 from the serum of the porcine with PMWS by PCR assay. Briefly, a pair of primers was designed according to the nucleotide sequence of PCV2 ORF2 (AF381175): forward primer F1 (5'-ACGGATATTGTAGTCCTGGT-3') and reverse primer R1 (5'CAAGGCTACCACAGTCAGAA-3'). This pair of primers amplifies a 472-bp DNA fragment of PCV2. Unexpectedly, a truncated amplicon with 1 nucleotide deletions was generated by DNA sequencing, which will result in frameshift mutation and a premature termination codon of ORF2 protein synthesis. According to the results above, we suspected that the existence of the

\footnotetext{
* Correspondence: kwh2003@263.net

'Institute of Veterinary Medicine, Jiangsu Academy of Agricultural

Sciences.Key Laboratory of Veterinary Biological Engineering and Technology, Ministry of Agriculture-National Center for Engineering Research of Veterinary Bio-products, Nanjing210014, China

Full list of author information is available at the end of the article
}

agent related with ORF2 sequences of PCV2 might be possible. Thus, inverse PCR was carried out with a pairs of primers based on DNA sequence of the amplicon, F2: 5'-TGTAGACCACGTAGGCCTCGG-3', R2: 5'-GGTTT GTATCCTCAGCCAAAG-3'. Then, the sequences of PCR generated fragments were assembled into consecutive sequence by using DNAMAN software (Version 5.2.2, Lynnon Biosoft, 1994).

Using inverse PCR bands should only be amplified if the agent genome is circular. The exception to this would be if there was non-specific binding of one of the primers. This is very unlikely when fragments have been amplified with two different primer sets but we still designed another pair of primers based on the sequences assembled to amplify the agent complete genome containing overlapping regions to verify.

F3: 5-TTAAAGACCCCCCACTTAAACCCTAAAT GA-3', and R3: 5'-AGTGGGGGGTCTTTAAGATTAAA TTCTCTG-3'. (Figure 1).

The novel PCV2-like agent (P1) was determined with a circle DNA genome of 648 nucleotides. The phylogenetic analysis showed that the virus P1 closely related to the known virus is PCV. It showed $98.42 \%$ of nucleotide homology with PCV2 BF isolate. The partial sequence data of P1 have been submitted to GenBank (EF514716), except 5'terminal 22 nt--_-_"ggatccactagtaacggccgcc". P1 genome has three possible open reading frames (ORF), capable of encoding amino acids of $12.5 \mathrm{kD}$ (ORF1), $3.0 \mathrm{kD}$ (ORF2) and $3.9 \mathrm{kD}$ (ORF3), respectively [7]. P1 has high homologous sequences of 
ORF2 of PCV2 and ORF3 of P2, another novel porcine circovirus-like agent [8]. The genome structure suggests that P1 and P2 might belong to a new virus family. So far, Very little is known about the epidemiology of P1. Therefore, the main objective of the present work was to determine the prevalence of $\mathrm{P} 1$.

\section{Materials and methods}

Initially, 248 pig sera corresponding to 6 non-related, different size herds sampled during years 2009 and 2010 were used for this study. Specifically, these consisted of 4 herds (A, B, C, D) in 2009, and 2 herd (E, F) in 2010, and the herds were located in the north western $(\mathrm{Su}$ qian), eastern (yancheng and Nantong), southern and central (Nanjing, zhenjiang, and wuxi) parts of Jiangsu province (Figure 2). The pigs were between 10 and 120 days of age and submitted to clinic examination because of different clinicopathological conditions, including wasting, respiratory distress, diarrhoea, and ochrodermia. Sera samples were stored at $-20^{\circ} \mathrm{C}$ for viral DNA extraction and PCR analysis.

For the viral DNA extraction, $300 \mu \mathrm{L}$ of cell lysis buffer $(20 \mathrm{mM}$ EDTA, $0.5 \%$ sodium dodecyl sulphate (SDS) and $200 \mu \mathrm{g} / \mathrm{ml}$ proteinase $\mathrm{K}$ ) was mixed with the 300 $\mu \mathrm{L}$ serum. Thoroughly vortexed and incubated at $50^{\circ} \mathrm{C}$ for $2 \mathrm{~h}$. Following incubation, DNA was extracted by conventional phenol -chloroform methods.

The specific P1 DNA was determined by using onestep PCR assay targeting complete nucleotide sequence of viral DNA-genome. The primers used for PCR reactions were previously designed [7]. Briefly, the PCR was performed in a $25 \mu \mathrm{L}$ final volume containing $2.5 \mu \mathrm{L}$ of viral template DNA, 10 pmol of forward primer F3 and reverse primer R3, $2.5 \mathrm{mM}$ dNTPs and $0.75 \mathrm{U}$ DNA Polymerase. The amplification was performed using a PCR thermal cycler (TaKaRa) and was initiated by heating for $5 \mathrm{~min}$ at $94^{\circ} \mathrm{C}$, followed by 40 cycles denaturation at $94^{\circ} \mathrm{C}$ for $45 \mathrm{~s}$, annealing at $58^{\circ} \mathrm{C}$ for $45 \mathrm{~s}$, and elongation at $72^{\circ} \mathrm{C}$ for $45 \mathrm{~s}$. The reaction ended with a final extension step at $72^{\circ} \mathrm{C}$ for $10 \mathrm{~min}$. Finally, $15 \mu \mathrm{L}$ of PCR product was run on $1.5 \% \mathrm{TAE}$-agarose gel stained with ethidium bromide $(0.5 \mu \mathrm{g} / \mathrm{mL})$. Positive DNA fragments of specific size (approximately $660 \mathrm{bp}$ ) were excised from the agarose gel and purified by using AxyPrep $^{\mathrm{TM}}$ DNA Gel Extraction kit (Hangzhou, China), and finally TA-cloned into vector pMD-18 T (TaKaRa) for sequencing. Three or 4 PCR positive samples for each pig herd were selected for sequence identification.

\section{Results}

Of the 248 serum specimens obtained from swine, 47 (19\%) were P1-positive by PCR assay, whilst 3(50\%) were positive for P1 among 6 farms. Prevalence values vary from $0 \%$ to $50 \%$ in pig herds. The prevalence results of P1 in six different geographical regions in Jiangsu are shown in Table 1. P1 infection rate of the pigs differed with their ages as Table 2 . There was significant difference on the prevalence of different age stage, being $50.0 \%$ (13/26) (10-30 days), $11.1 \%(3 / 27)$ (40-60 days), $22.2 \%$ (6/27) (70-90 days) and $16.0 \%(4 / 25)$ (100-120 days), respectively. 10-30 days has the highest number of infected pigs in herd F infected with P1.

Some of the PCR products were cloned and sequenced. All of the P1 strains was 648 bp in size and shared more than $97.2 \%$ nucleotide homology with the isolated P1 strain submitted to GenBank (EF514716).

\section{Discussion}

PMWS, a new emerging and multifactorial disease in swine, was first recognized in North America in 1991 [9]. Since then, this disease has been diagnosed globally and devastated almost every pig-producing area of the world [10]. A role of PCV2 in the etiology of PMWS was first observed in Canada in 1991, and described in the late 1990s. Although PCV2 infection has been associated with PMWS, the role of PCV2 infection in the pathogenesis of PMWS is uncertain. To date, PCV-2 infection is regarded as a necessity in PMWS cases, other cofactors are necessary to evoke disease. PMWSaffected pigs exhibit a wide spectrum of concomitant infections with PCV2, such as porcine parvovirus $[11,12]$, porcine reproductive and respiratory syndrome virus (PRRSV) [13,14], TTV [15] and Mycoplasma hyopneumoniae [16], all may enhance PCV2-associated lesions and develop whole complex clinical symptom of PMWS under experimental and field conditions [17].

The difficulties in reproducing the full spectrum of clinical signs and lesions associated with PMWS using PCV2 alone have resulted in a hypothesis that PMWS may be triggered by an unknown pathogen, popularly termed 'agent X', Of course, no such novel agent has been identified until now [18]. The finding of novel viral agents in the PMWS disease is challenging since there still are many open questions concerning the aetiology of the syndrome. From all the studied animals in the present study, 3 were co-infected with both PCV2 and P1, 10 were positive for PCV2 only (data not shown). Therefore, further studies needs to be conducted in order to see if the presence of the novel agent P1 described here, contributes to the development of PMWS solely and/or in synergy with PCV-2.

PCR was proved to be a useful tool for detecting PCV2 in clinical specimens because of its speed, specificity, and sensitivity. But challenges encountered by its specificity as to P1 occurrence, most of PCR assay reported previously would target the ORF2 region of the PCV2 genome, which shared high similarity nucleotide 

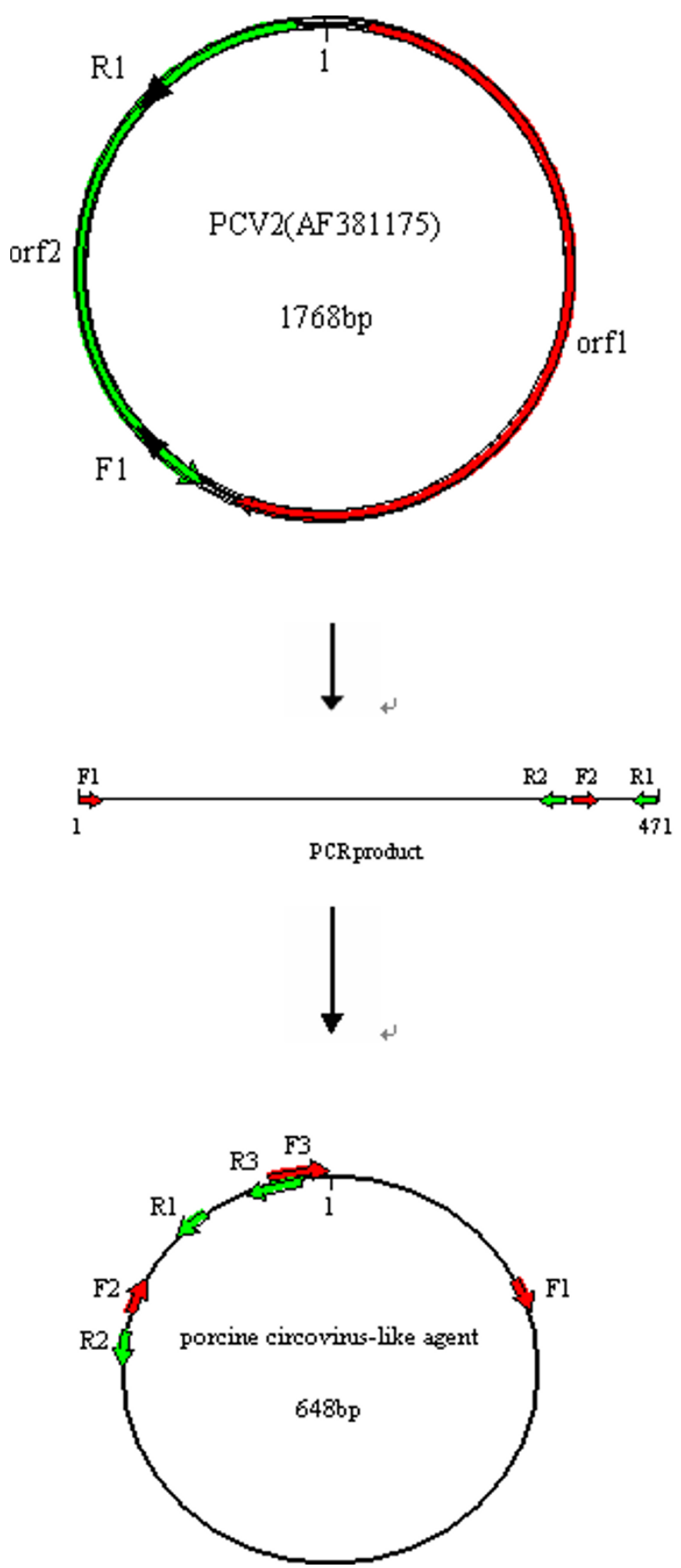

Figure 1 Schematic diagram of the PCR process to obtain porcine circovirus-like agent P1.

sequence with ORF1 of P1. It is vital to determine whether those PCR amplification fragments were produced by PCV 2 or by P1. The PCR assay described here should provide the ability to identify and differentiate between PCV2 and P1 and screen pigs for P1 infection. To our knowledge, this is the first report on epidemiology of P1 in China. Of course, to obtain the complete genome sequence of $\mathrm{P} 1$ and aid in further analysis of genomic features of $\mathrm{P} 1$, we used the pairs of primers F3 and R3 including an overlapping region in this study. Rather than amplify the entire 648 nt of P1, designing some primers amplifying smaller products may improve the sensitivity of the assay and be more suitable for epidemiological investigation of $\mathrm{P} 1$. 


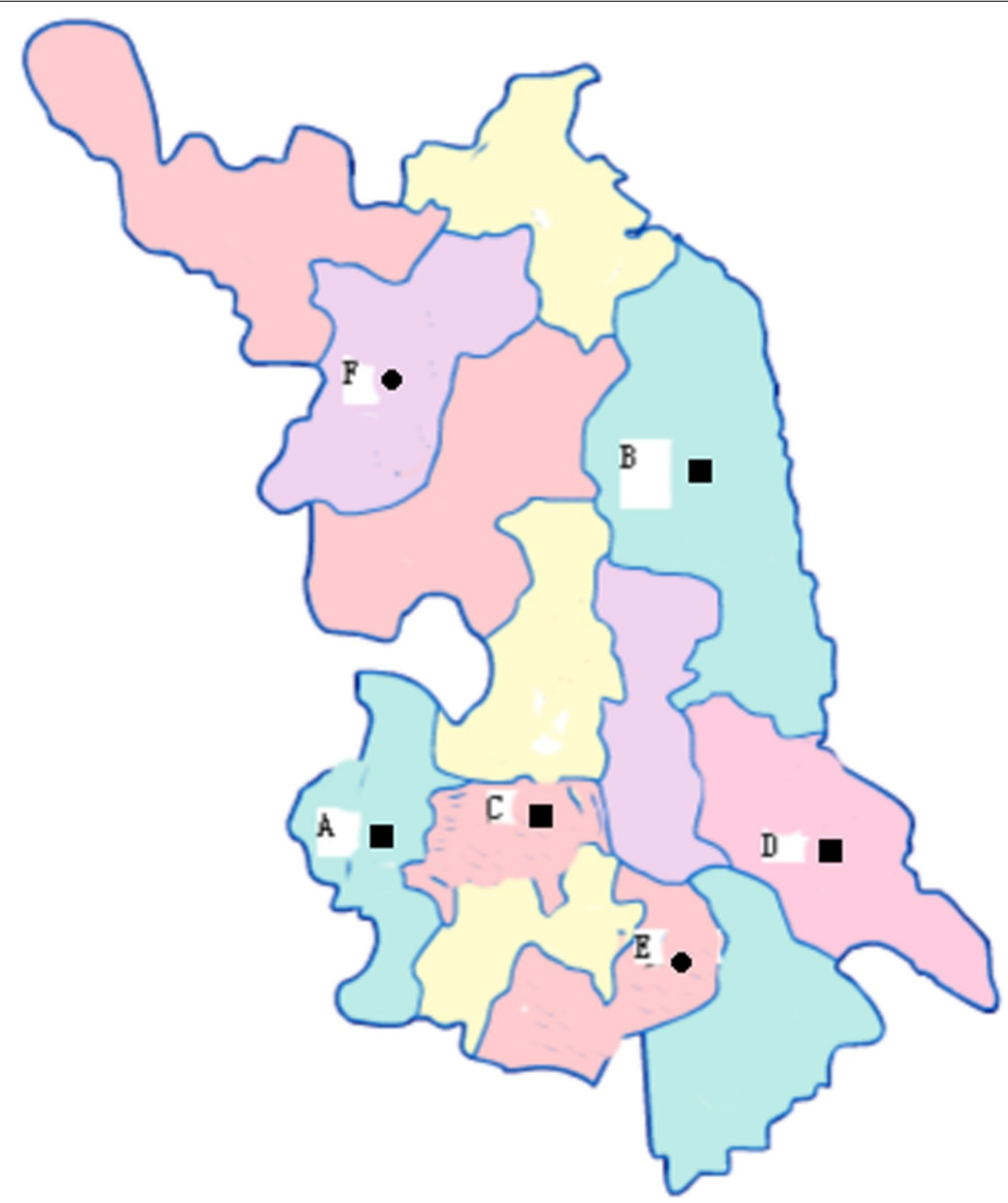

Figure 2 Geographic distribution of the pig herds involved in this study. Black sphere(•) represents samples collected in 2010 and black square $(-)$ represents samples collected in 2009. English alphabet represents the herds in different parts of the Jiangsu; A in Nanjing, B in Yancheng, $\mathrm{C}$ in Zhenjiang, D in Nantong, E in Wuxi, and F in Suqian.

In a previous study, $1.8 \%(5 / 278)$ of studied swine sera from China was shown to be P1-positive by a PCR detecting [7]. The difference in the prevalence of P1 $(19 \%, 47 / 248)$ obtained in our present study indicate that the P1 infection has became popular in pig herds.
Of course, very low copies of P1 DNA were also detected in some sera samples, the biological importance of the virus remains to be elucidated.

In summary, the present work contributes to the understanding of P1 epidemiology, including the 
Table 1 Number of positive pigs by P1 PCR in different herds and sera of pigs with PMWS

\begin{tabular}{lll}
\hline Pig group & No. tested pigs & No. PCR P1 positive pigs (\%) \\
\hline A & 20 & $10(50.0)$ \\
\hline$B$ & 40 & $11(27.5)$ \\
\hline$C$ & 20 & $0(0)$ \\
\hline$D$ & 15 & $0(0)$ \\
\hline E & 48 & $0(0)$ \\
\hline F & 105 & $26(24.8)$ \\
\hline
\end{tabular}

Table 2 The representative ages and the number of pigs in herd $\mathbf{F}$ tested for $\mathbf{P 1}$ in serum samples by PCR

\begin{tabular}{lll}
\hline Age of pigs(days) & No. tested pigs & No. P1-affected \\
\hline $10-30$ & 26 & 13 \\
\hline $40-60$ & 27 & 3 \\
\hline $70-90$ & 27 & 6 \\
\hline $100-120$ & 25 & 4 \\
\hline
\end{tabular}

establishment of PCR assay described here. Taking into account the present results, it seems evident that $\mathrm{P} 1$ infection is already widespread in Jiangsu and those 1030 days old pigs seem more likely to be infected with P1. Further studies should be investigated in larger scale data in order to determine the biological importance of P1.

\section{Acknowledgements}

This work was supported by the National Natural Science Foundation of China (NSFC, 30972184), and the Natural Science Foundation of Jiangsu Province (BK2008351).

\section{Author details}

${ }^{1}$ Institute of Veterinary Medicine, Jiangsu Academy of Agricultural Sciences:Key Laboratory of Veterinary Biological Engineering and Technology, Ministry of Agriculture-National Center for Engineering Research of Veterinary Bio-products, Nanjing210014, China. ${ }^{2}$ College of Veterinary Medicine, China Agricultural University, Beijing 100094, China.

\section{Authors' contributions}

LW contributed in the study design of the study and drafted manuscript. KH and $\mathrm{HY}$ were responsible for the planning of the study. ZY, AM, SZ, YN, XZ, and BL participated in clinical samples collection. XW and JZ participated in results analysis. RG and LL performed the work. JJ participated in revising the manuscript. All the authors read and approved the final manuscript.

\section{Competing interests}

The authors declare that they have no competing interests.

Received: 17 March 2011 Accepted: 15 December 2011 Published: 15 December 2011

\section{References}

1. Tischer I, Gelderblom H, Vettermann W, Koch MA: A very small porcine virus with circular single-stranded DNA. Nature 1982, 295:64-66.

2. Tischer I, Bode L, Peters D, Pociuli S, Germann B: Distribution of antibodies to porcine circovirus in swine populations of different breeding farms. Arch Virol 1995, 140(4):737-743.
3. Allan GM, McNeilly F, Kennedy S, Daft B, Clarke EG, Ellis JA, Haines DM, Meehan BM, Adair BM: Isolation of porcine circovirus-like viruses from pigs with a wasting disease in the USA and Europe. I Vet Diagn Invest 1998, 10(1):3-10.

4. Ellis J, Hassard L, Clark E, Harding J, Allan G, Willson P, Strokappe J, Martin K, McNeilly F, Meehan B, Todd D, Haines D: Isolation of circovirus from lesions of pigs with postweaning multisystemic wasting syndrome. Can Vet J 1998, 39:44-51.

5. Harding JCS, Clark EG: Recognizing and diagnosing postweaning multisystemic wasting syndrome (PMWS). J Swine Health Prod 1997, 5:201-203.

6. Rosell C, Segalés J, Plana-Duran J, Balasch M, Rodriguez-Arrioja GM, Kennedy S, Allan GM, McNeilly F, Latimer KS, Domingo M: Pathological, immunohistochemical, and in situ hybridization studies of natural cases of postweaning multisystemic wasting syndrome (PMWS) in pigs. $J$ Comp Pathol 1999, 120:59-78.

7. Wen L, He K, Yang H: Sequencing and analysis of complete genome of a porcine circovirus type 2-like agent P1. Sci Agric Sin 2010, 43(2):411-416, (in Chinese with English abstract).

8. Wen L, He K, Yang H, Ni Y, Zhang X, Guo R, Pan Q: Complete nucleotide sequence of a novel porcine circovirus-like agent and its infectivity in vitro. Sci China C Life Sci 2008, 51(5):453-458.

9. Harding JC: Post-weaning multisystemic wasting syndrome: preliminary epidemiology and clinical findings. Proceedings of the Western Canadian Association on Swine Practice 199621.

10. Segalés J, Allan GM, Domingo M: Porcine circovirus diseases. Anim Health Res Rev 2005, 6:119-142.

11. Allan GM, Kennedy S, McNeilly F, Foster JC, Ellis JA, Krakowka SJ, Meehan BM, Adair BM: Experimental reproduction of severe wasting disease by co-infection of pigs with porcine circovirus and porcine parvovirus. J Comp Pathol 1999, 121:1-11.

12. Krakowka S, Ellis JA, Meehan B, Kennedy S, McNeilly F, Allan G: Viral wasting syndrome of swine: experimental reproduction of postweaning multisystemic wasting syndrome in gnotobiotic swine by coinfection with porcine circovirus 2 and porcine parvovirus. Vet Pathol 2000, 37:254-263.

13. Allan GM, McNeilly F, Ellis J, Krakowka S, Meehan B, McNair I, Walker I, Kennedy S: Experimental infection of colostrum deprived piglets with porcine circovirus 2 (PCV2) and porcine reproductive and respiratory syndrome virus (PRRSV) potentiates PCV2 replication. Arch Virol 2000, 145:2421-2429.

14. Harms PA, Sorden SD, Halbur PG, Bolin SR, Lager KM, Morozov I, Paul PS: Experimental reproduction of severe disease in $C D / C D$ pigs concurrently infected with type 2 porcine circovirus and porcine reproductive and respiratory syndrome virus. Vet Pathol 2001, 38:528-539.

15. Ellis J, Allan G, Krakowka S: Effect of coinfection with genogroup 1 porcine torque teno virus on porcine circovirus type 2-associated postweaning multisystemic wasting syndrome in gnotobiotic pigs. Am J Vet Res 2008, 69(12):1608-1614.

16. Opriessnig T, Thacker EL, Yu S, Fenaux M, Meng XJ, Halbur PG: Experimental reproduction of postweaning multisystemic wasting syndrome in pigs by dual infection with Mycoplasma hyopneumoniae and porcine circovirus type 2. Vet Pathol 2004, 41(6):624-640.

17. Pogranichniy RM, Yoon KJ, Harms PA, Sorden SD, Daniels M: Case-control study on the association of porcine circovirus type 2 and other swine viral pathogens with postweaning multisystemic wasting syndrome. $J$ Vet Diagn Invest 2002, 14(6):449-456.

18. Lohse L, Botner A, Hansen AS, Frederiksen T, Dupont K, Christensen CS, Baekbo P, Nielsen J: Examination for a viral co-factor in postweaning multisystemic wasting syndrome (PMWS). Vet Microbiol 2008, 129:97-107.

doi:10.1186/1743-422X-8-543

Cite this article as: Wen et al:: Prevalence of porcine circovirus-like agent P1 in Jiangsu, China. Virology Journal 2011 8:543. 